\title{
Resource Utilization of Patients with Parkinson's Disease in the Late Stages of the Disease in Germany: Data from the CLaSP Study
}

\author{
Christopher Kruse $^{1} \cdot$ Sabrina Kretschmer ${ }^{1,2} \cdot$ Anna Lipinski $^{1,2} \cdot$ Malte Verheyen $^{1} \cdot$ David Mengel $^{3}$. \\ Monika Balzer-Geldsetzer ${ }^{1,2} \cdot$ Stefan Lorenzl ${ }^{4,5}$. Carmen Richinger ${ }^{5}$. Christian Schmotz ${ }^{5}$. Lars Tönges ${ }^{6,7}$. \\ Dirk Woitalla $^{8} \cdot$ Stephan Klebe $^{9} \cdot$ Anette Schrag $^{10} \cdot$ Richard Dodel $^{1,2}$
}

Accepted: 18 February 2021 / Published online: 19 March 2021

(c) The Author(s) 2021

\begin{abstract}
Objective The Care of Late-Stage Parkinsonism (CLaSP) study aimed to collect qualitative and standardized patient data in six European countries (France, Germany, Netherlands, Portugal, UK, Sweden) to enable a detailed evaluation of the underexplored late stages of the disease (Hoehn and Yahr stage >3) using clinical, neuropsychological, behavioral, and health economic data. The aim of this substudy was to provide a health economic evaluation for the German healthcare system.

Methods In Germany, 228 patients were included in the study. Costs were calculated from a societal perspective for a 3 -month period. Univariate analyses were performed to identify cost-driving predictors. Total and direct costs were analyzed using a generalized linear model with a $\gamma$-distributed dependent variable and log link function. Indirect costs were analyzed using a binomial generalized linear model with probit link function.

Results The mean costs for the 3-month period were approximately $€ 20,000$. Informal care costs and hospitalization are approximately $€ 11,000$ and $€ 5000$. Direct costs amounted to $89 \%$ of the total costs, and the share of indirect costs was $11 \%$. Independent predictors of total costs were the duration of the disease and age. The duration of the disease was the main independent predictor of direct costs, whereas age was an independent predictor of indirect costs.

Discussion Costs in the late stage of the disease are considerably higher than those found in earlier stages. Compared to the latter, the mean number of days in hospital and the need for care is increasing. Informal caregivers provide most of the care. Clinical Trial Registration The protocol was registered at ClinicalTrials.gov as NCT02333175 on 7 January, 2015.
\end{abstract}

\section{Key Points for Decision Makers}

Resource use of late-stage parkinsonism has not been sufficiently investigated; the CLaSP study provides the first detailed health economic insight.

Resource use increases in the late stages compared to the earlier stages, while the duration of the disease and the age of the patients were independent predictors of costs.

A large burden is placed on relatives in the form of informal care and only $25 \%$ of the patients receive professional care.

Richard Dodel

richard.dodel@uk-essen.de

Extended author information available on the last page of the article

\section{Introduction}

Parkinson's disease (PD) is a chronic degenerative disease of the nervous system. It is the second most common neurodegenerative disease and affects approximately 1.4 million people in Europe (2016) [1, 2]. The main characteristics of the disease are an asymmetric occurrence of bradykinesia, tremor, and rigidity. As PD progresses, non-motor features such as dementia, depression, dysautonomia, and urinary dysfunction occur more frequently and are often responsible for the disability of patients in the advanced stages of the disease [3-5]. The categorization based on disease stages was first proposed by Hoehn and Yahr (HY) [6]. The stages range from I to $\mathrm{V}$, with stages IV and $\mathrm{V}$ referring to the late stage of the disease. Patients in these stages cannot cope with the activities of daily living on their own and have thus become dependent on their caregiver (CG) [3] .

The early stages of the disease have been investigated in a large number of studies, and detailed assessments are 
available on the health and social needs of the patients. Table 1 of the Electronic Supplementary Material (ESM) shows an overview of the major cost studies. Depending on the country, the annual mean cost per patient in Europe was between $€ 5240$ and $€ 19,640$ [7-11]. In the USA, the cost ranged from $\$ 18,528$ to $\$ 32,175$ [12-14], in Australia, the cost was AUD7020 [15], and in Singapore \$10,129 [16]. Direct costs accounted for 39-90\% of these costs [7-10, 14]. The late stages of PD, however, data are sparse [17]. If a breakdown of costs by disease severity was provided, the sample size of late-stage patients was small. As a result, the medical and social needs of the patients, as well as the societal costs are also insufficiently known. Generally, studies with smaller sample sizes of patients with late-stage PD than our study tend to have an increased use of health as well as social care resources (hospitalization and institutionalization) [8, 18-20] and a high need for informal care with increased CG burden [21, 22] compared with the earlier stages. The annual mean cost of late-stage patients in Europe was approximately between $€ 2000$ and $€ 18,000$; however, the results were based on a sample size of late-stage patients with a range of 3-23 [7, 8]. Because of the paucity of data on the economic burden of patients in the late stage of PD, we aimed to evaluate the health economic burden of the disease in the late stages using data from the Care of Late-Stage Parkinsonism (CLaSP) study [23].

\section{Patients and Methods}

\subsection{Study Design}

The CLaSP study is a longitudinal multicenter cohort study from six European countries (Bordeaux, France; Marburg, Essen, Munich, Germany; Nijmegen, the Netherlands; Lisbon, Portugal; Lund, Sweden; London, Luton, UK) of patients with late-stage PD and their informal CG. Further information on the clinical study can be found in the study protocol [23].

\subsection{Inclusion and Exclusion Criteria}

Patients were eligible for the study if they had a disease duration of at least 7 years and were assigned to HY stage IV or V in the "on" state or had developed significant disability (Schwab and England Scale $\leq 50 \%$ ) in the "on" state. The "on" state of PD is when a patient"s symptoms are controlled in the presence of drug therapy and when they feel at their most capable. The 'off' state of PD is when PD symptoms come back and affect patients the most. Patients diagnosed with symptomatic PD were excluded. As the analysis refers to the German healthcare system, foreign data were also excluded. Furthermore, only baseline data were used for the analysis.

\subsection{Outcome Measures}

The health economic data were collected by a standardized questionnaire already used in previous health economic costof-illness studies [7].

\subsubsection{Clinical Assessments}

The Unified Parkinson's Disease Rating Scale was used to address the sections mentation, behavior and mood, activities of daily living, motor examination, and complications of therapy. The minimum value of 0 indicates no disability at all, while the maximum value of 199 indicates the worst possible result. In addition, the Unified Parkinson's Disease Rating Scale HY Scale was used to describe the stage of PD severity of the disease. Patients at stage III have a mild-to-moderate bilateral disease. They have some postural instability and are physically independent. At stage IV, patients have a severe disability, but they are still able to walk or stand unassisted. Stage V patients are bound to the wheelchair or are bedridden unless aided [6]. The Schwab and England Scale measures the ability to perform activities of daily living. A decreasing percentage value indicates a deterioration. Patients with a score of $50 \%$ are already more dependent and need help with half of their chores. They have difficulty with all activities of daily living. With a score of $40 \%$, the patients are very dependent. They can do all chores with assistance but few alone. At 30\%, they need substantial help. With effort, they can sometimes do a few chores alone. Patients at 20\% can do nothing alone. They only can do some slight help with some chores. They are severe invalids. A score of $10 \%$ indicates total dependence and helplessness. At 0\%, vegetative functions such as swallowing and bladder and bowel function are not functioning, and patients are bedridden [24].

\subsubsection{Health-Related Quality of Life}

Health-related quality of life was evaluated using the self-completed generic EuroQol instrument. The patients answered the EQ-5D-3L questionnaire and a visual analog scale (EQ-VAS). The EQ-5D-3L questionnaire concerns mobility, self-care, usual activities, pain/discomfort, and anxiety/depression [25]. Each of these domains can be evaluated at three levels. As a result, $3^{5}(=243)$ different conditions of health-related quality of life can be defined. 
The values range from less than 0 (where 0 is a health state equivalent to death) to 1 (perfect health) [26].

\subsection{Cost Assessment}

Costs were calculated from a societal perspective and were divided into direct and indirect costs [27]. Unless stated otherwise, the assumed costs refer to the year 2016 (Table 1). The costs were calculated for a 3-month period.

\subsubsection{Direct Costs}

2.4.1.1 Outpatient Medical Visits Consulted physicians' specific costs per visit were calculated [28] with respect to private healthcare compensation [29]. Afterwards, specific costs were multiplied by the number of visits related to the examined disease over the last 3 months.

2.4.1.2 Hospital and Rehabilitation Costs for inpatient care in hospitals were calculated on a daily basis. In addition to the operating costs, the capital costs were also taken into account $[28,30]$. Costs for rehabilitation were differentiated into inpatient and outpatient rehabilitation on a daily basis [28].

2.4.1.3 Ancillary Therapy Costs for physiotherapy, occupational therapy, speech training, and further therapy apart from medication were also estimated by specific costs per visit [28].

2.4.1.4 Medical Devices and Consumables Costs for medical devices and consumables were based on the reported expenses of the statutory health company [31].

2.4.1.5 Formal Care and Informal Care Specific costs depending on the level of care were calculated for semiresidential day care, short-term care, and night care per day. The average remuneration depending on care levels and investment costs dates from 2015 and was inflated to 2016 [32]. Costs for outpatient home care were the averaged and deflated (from 2018 to 2016) official compensation agreements from the Verband der Ersatzkassen (VDEK) for welfare and private care associations in Bavaria [32-34]. Because the patients only stated on how many days they received outpatient home care, we had to estimate the average length of stay of a patient and the average number of visits per day. We determined the average duration per visit and the number of visits per day from the accounting data of a provider of outpatient care depending on the level of care [35]. Costs for 24-h care $(€ 12.33 / \mathrm{h})$ and informal care were based on the minimum wage within the care sector plus ancillary costs.
2.4.1.6 Medication Medication costs were based on the official drug price list, Rote Liste 2016 [36]. The cheapest drug of the respective active ingredient was calculated and used to determine the costs. The suppliers varied.

\subsubsection{Indirect Costs}

Within indirect costs, productivity losses for early retirement, unemployment, part-time employment, and sick leave because of PD were calculated according to the human capital approach. For early retirement and unemployment, calendar days before the 67 th birthday within the study period were multiplied by $€ 121.74$. The number of days missed because of sick leave was multiplied by $€ 201.98$ (based on 220 working days in 2016). These values were derived from the average annual gross wage in Germany $(€ 44,436)$ [37].

\subsection{Missing Values}

Approximately $97.5 \%$ of the values were complete. Nevertheless, in 123 of the 228 cases, missing values occurred. The latter were estimated by multiple imputation using the Markov Chain Monte Carlo method for five additional data samples.

21 of the included patients indicated a hospital stay without being able to quantify the length of stay. In these cases, the length was taken from the mean length of stay in the DRG Fallpauschalen-Katalog based on the reason for hospitalization [38].

Because of an accumulation of missing values and irregular answers, the variable informal care was examined separately. In total, $60 / 228$ values were missing. In 32/60 cases, there was a CG who did not participate. In $28 / 60$ cases, the data were missing for unknown reasons.

In 61 cases, the sum of the informal caring time was greater than $24 \mathrm{~h}$. The first step therefore was to establish that informal care could not exceed $16 \mathrm{~h}$ ( $8 \mathrm{~h}$ of sleep). As the data on informal care were corrected downwards and the distribution was unique, a multiple imputation was not used for missing values. Instead, we tried to include that in 32 cases, we knew there was a CG who did not participate. In these cases, the informal care time was estimated with the corrected mean informal care time of the remaining patients $(11.81 \mathrm{~h} /$ day $)$. Values that were missing for unknown reasons were excluded.

\subsection{Statistical Analysis}

The statistical analysis was performed using IBM SPSS Statistics, Version 26.0.0.0 (IBM, Armonk, New York, USA). To check the data for normal distribution, the Kolmogorov-Smirnov test and Shapiro-Wilk test were used $(p<$ $0.05)$ [39]. The total and direct cost data were positively 
Table 1 Unit costs for consumption of resources

\begin{tabular}{|c|c|c|c|c|}
\hline Parameter & Value & Unit & Year & References \\
\hline General practitioner & 19.53 & $€ /$ visit & 2016 & Bock et al., 2015 [28] \\
\hline Neurologist & 66.62 & $€ /$ visit & 2016 & Bock et al., 2015 [28] \\
\hline Urologist & 27.17 & $€ /$ visit & 2016 & Bock et al., 2015 [28] \\
\hline Ear, nose, and throat specialist & 28.20 & $€ /$ visit & 2016 & Bock et al., 2015 [28] \\
\hline Dermatologist & 21.89 & $€ /$ visit & 2016 & Bock et al., 2015 [28] \\
\hline Radiologist & 217.51 & $€ /$ visit & 2016 & Bock et al., 2015 [28] \\
\hline Physician consultation average & 28.87 & $€ /$ visit & 2016 & Bock et al., 2015 [28] \\
\hline $\begin{array}{l}\text { Multiplier outpatient medical sector (private and statutory } \\
\text { health insurance) }\end{array}$ & 3.72 & Percent & 2016 & Bock et al., 2015 [28]; Krauth et al., 2005 [29] \\
\hline Physiotherapy & 18.09 & $€ /$ visit & 2016 & Bock et al., 2015 [28] \\
\hline Occupational therapy & 39.93 & $€ /$ visit & 2016 & Bock et al., 2015 [28] \\
\hline Speech training & 41.97 & $€ /$ visit & 2016 & Bock et al., 2015 [28] \\
\hline Ancillary therapy average & 20.92 & $€ /$ visit & 2016 & Bock et al., 2015 [28] \\
\hline $\begin{array}{l}\text { Multiplier ancillary therapy (private and statutory health insur- } \\
\text { ance) }\end{array}$ & 1.31 & Percent & 2016 & Bock et al., 2015 [28] \\
\hline Multiplier copayments ancillary therapy & 2.25 & Percent & 2016 & Bock et al., 2015 [28] \\
\hline Hospital stay (inpatient) & 692.77 & $€ /$ day & 2016 & $\begin{array}{l}\text { Bock et al., } 2015 \text { [28]; Krauth et al., } 2005 \\
\text { [29]; Bruckenberger, } 1997 \text { [30] }\end{array}$ \\
\hline Rehabilitation facility (inpatient) & 144.46 & $€ /$ day & 2016 & Bock et al., 2015 [28] \\
\hline Rehabilitation facility (outpatient) & 58.52 & $€ /$ day & 2016 & Bock et al., 2015 [28] \\
\hline Medical devices & & & & BARMER, 2018 [31] \\
\hline \multicolumn{5}{|l|}{ Day care outside home } \\
\hline Care level 1 & 45.02 & $€ /$ day & 2016 & Bock et al., 2015 [28] \\
\hline Care level 2 & 52.51 & $€ /$ day & 2016 & Bock et al., 2015 [28] \\
\hline Care level 3 & 59.77 & $€ /$ day & 2016 & Bock et al., 2015 [28] \\
\hline \multicolumn{5}{|l|}{ Day care inside home } \\
\hline Compensation & 32.61 & $€ /$ hour & 2016 & Bock et al., 2015 [28] \\
\hline Travel flat-rate & 4.26 & $€ /$ visit & 2016 & Bock et al., 2015 [28] \\
\hline \multicolumn{5}{|l|}{ Average operation time (depending on care level) } \\
\hline Care level 1 & 0.36 & hours/visit & 2019 & Pflegebüro Bahrenberg Gruppe, 2019 [35] \\
\hline Care level 2 & 0.38 & hours/visit & 2019 & Pflegebüro Bahrenberg Gruppe, 2019 [35] \\
\hline Care level 3 & 0.37 & hours/visit & 2019 & Pflegebüro Bahrenberg Gruppe, 2019 [35] \\
\hline \multicolumn{5}{|l|}{ Average number of operations (depending on care level) } \\
\hline Care level 1 & 2.00 & operations/day & 2019 & Pflegebüro Bahrenberg Gruppe, 2019 [35] \\
\hline Care level 2 & 2.14 & operations/day & 2019 & Pflegebüro Bahrenberg Gruppe, 2019 [35] \\
\hline Care level 3 & 3.17 & operations/day & 2019 & Pflegebüro Bahrenberg Gruppe, 2019 [35] \\
\hline \multicolumn{5}{|l|}{ Night care } \\
\hline Care level 1 & 65.80 & $€ /$ day & 2016 & Bock et al., 2015 [28] \\
\hline Care level 2 & 76.59 & $€ /$ day & 2016 & Bock et al., 2015 [28] \\
\hline Care level 3 & 89.67 & $€ /$ day & 2016 & Bock et al., 2015 [28] \\
\hline \multicolumn{5}{|l|}{ Respite or short-term care admission } \\
\hline Care level 1 & 67.49 & $€ /$ day & 2016 & Bock et al., 2015 [28] \\
\hline Care level 2 & 83.38 & $€ /$ day & 2016 & Bock et al., 2015 [28] \\
\hline Care level 3 & 99.57 & $€ /$ day & 2016 & Bock et al., 2015 [28] \\
\hline 24-h care (minimum wage within care sector) & 12.33 & $€ /$ hour & 2016 & Bock et al., 2015 [28] \\
\hline Informal care (minimum wage within care sector) & 12.33 & $€ /$ hour & 2016 & Bock et al., 2015 [28] \\
\hline Unemployment due to illness & 121.74 & $€ /$ day & 2016 & Statistisches Bundesamt (Destatis), 2019 [37] \\
\hline Day of illness (based on 220 working days) & 201.98 & $€ /$ day & 2016 & Statistisches Bundesamt (Destatis), 2019 [37] \\
\hline Medication & & & 2016 & Rote Liste Service GmbH, 2016 [36] \\
\hline
\end{tabular}


skewed. In terms of indirect costs, only a small number of patients showed productivity losses. This resulted in a different distribution, in which no indirect costs arose for the majority.

Accordingly, for total, direct, indirect costs, and informal care, bias-corrected and accelerated bootstrap 95\% confidence intervals with 1000 replications were calculated from the original data set [40]. A univariate analysis was conducted to identify potential cost drivers. Differences between the means of two or more independent groups were tested with the nonparametric Mann-Whitney U test and the Kruskal-Wallis $\mathrm{H}$ test, respectively. For exploratory reasons, the significance level was set at $5 \%$ and was not adjusted, for example, by a Bonferroni correction.

The factors previously identified as potential cost drivers were then examined in a multiple regression analysis. For total and direct costs, a generalized linear model with a $\gamma$-distributed dependent variable and a log link function was used [41]. For indirect costs, a binomial generalized linear model with a probit link function was used. To avoid a distortion of total costs due to the very different distribution of informal care, the latter was included in a second analysis and examined separately (Table 5).

For total and direct costs, univariate and multiple regression analyses were performed using both the original data and the imputed data sets (Tables 2-5 and 8-9 of the ESM). No data had to be imputed for indirect costs.

\section{Results}

\subsection{Patient Characteristics}

Table 2 shows the patient characteristics. A total of 228 patients were enrolled in the study from three centers in Germany: 120 Munich (53\%), 81 Marburg (36\%), and 27 Essen (12\%). Of these, 97 (43\%) were female and $131(57 \%)$ were male. The mean age was $74.06 \pm 8.39$ years. On average, the disease duration was $12.64 \pm 8.14$ years. Seventy-two (32\%)
Table 2 Baseline information about patients' disease severity

\begin{tabular}{|c|c|c|c|c|c|c|}
\hline Parameter & $n$ & Missing & Mean & $\begin{array}{l}\text { Standard } \\
\text { deviation }\end{array}$ & Minimum & Maximum \\
\hline \multicolumn{7}{|l|}{ Sex } \\
\hline Female & 97 & - & - & - & - & - \\
\hline Male & 131 & & - & - & - & - \\
\hline Age & 227 & 1 & 74.06 & 8.39 & 46.00 & 95.00 \\
\hline \multicolumn{7}{|l|}{ UPDRS } \\
\hline \multicolumn{7}{|l|}{ Hoehn and Yahr } \\
\hline III & 14 & & & & & \\
\hline IV & 142 & - & - & - & - & - \\
\hline $\mathrm{V}$ & 72 & & - & - & - & - \\
\hline \multicolumn{7}{|l|}{ Schwab and England } \\
\hline 0.7 & 2 & - & - & - & - & - \\
\hline 0.6 & 7 & & - & - & - & - \\
\hline 0.5 & 56 & & - & - & - & - \\
\hline 0.4 & 35 & & - & - & - & - \\
\hline 0.3 & 55 & & - & - & - & - \\
\hline 0.2 & 34 & & - & - & - & - \\
\hline 0.1 & 24 & & - & - & - & - \\
\hline 0 & 14 & & - & - & - & - \\
\hline Mentation, behavior, and mood & 228 & 0 & 5.14 & 3.00 & 0.00 & 13.00 \\
\hline Activities of daily living & 228 & 0 & 26.84 & 7.99 & 7.00 & 47.00 \\
\hline Motor examination & 228 & 0 & 48.98 & 17.36 & 10.00 & 92.00 \\
\hline Complications of therapy & 228 & 0 & 4.63 & 3.79 & 0.00 & 16.00 \\
\hline EQ-5D-3L & 227 & 1 & 0.45 & 0.27 & -0.21 & 0.90 \\
\hline \multicolumn{7}{|l|}{ Insurance status } \\
\hline Private health insurance & 39 & 4 & - & - & - & - \\
\hline Statutory health insurance & 184 & & - & - & - & - \\
\hline Duration of the disease (years) & 222 & 6 & 12.64 & 8.14 & 1.00 & 51.00 \\
\hline
\end{tabular}

UPDRS Unified Parkinson's Disease Rating Scale 
were assigned to stage HY V, 142 patients (62\%) to HY IV, and 14 entries (6\%) to HY III.

\subsection{Costs of Illness}

The breakdown of health-related resource consumption can be seen in Table 3. From the societal perspective, the total cost average was $€ 9657$ per quarter for the original data set. The costs extrapolated to 1 year were therefore $€ 38,628$. The calculated bootstrap 95\% confidence interval was between $€ 8362$ and $€ 11,193$. The cost of informal care was $€ 10,964$.

\subsection{Direct Costs}

The mean direct costs were $€ 8749$ (90.6\% of total costs), with each patient causing health-related direct costs (Table 3 ). The bootstrap 95\% confidence interval was between $€ 7437$ and $€ 10,744$.

\subsubsection{Inpatient Stay}

With $€ 4,964$ (51.4\%), the hospital stays caused approximately half of the total costs. A total of $52 \%$ of the patients were hospitalized within the 3-month study period. On average, the patients spent 7.2 days in hospital.

Table 3 Resource use per patient in the 3-month period

\begin{tabular}{|c|c|c|c|c|c|c|c|c|}
\hline \multirow[t]{3}{*}{ Parameter } & \multicolumn{6}{|c|}{ Original data set } & \multicolumn{2}{|c|}{ Imputed data sets } \\
\hline & \multirow[t]{2}{*}{$n(\%)^{\mathrm{b}}$} & \multirow[t]{2}{*}{ Mean $(€)$} & \multicolumn{2}{|c|}{$95 \% \mathrm{CI}^{\mathrm{a}}$} & \multirow[t]{2}{*}{ Median $(€)$} & \multirow[t]{2}{*}{ Total costs $(\%)$} & \multirow[t]{2}{*}{ Mean $(€)$} & \multirow[t]{2}{*}{ Total costs $(\%)$} \\
\hline & & & Lower & Upper & & & & \\
\hline Direct costs & 100 & 8749 & 7332 & 10,400 & 6567 & 90.6 & 8033 & 89.3 \\
\hline Physicians & 88.6 & 177 & 153 & 203 & 124 & 1.8 & 179 & 2.0 \\
\hline Primary physician & 85.9 & 110 & 94 & 129 & 67 & 1.1 & 113 & 1.3 \\
\hline Further physicians & 48.1 & 62 & 47 & 79 & 0 & 0.6 & 66 & 0.7 \\
\hline Ancillary therapy & 78.2 & 639 & 566 & 711 & 434 & 6.7 & 641 & 7.1 \\
\hline Medical aids & 34.2 & 188 & 140 & 237 & 0 & 1.9 & 192 & 2.1 \\
\hline Hospital & 52.4 & 4964 & 4039 & 5955 & 1386 & 51.4 & 4992 & 55.5 \\
\hline Rehabilitation & 8.1 & 206 & 99 & 328 & 0 & 2.1 & 214 & 2.4 \\
\hline Inpatient & 5.8 & 203 & 103 & 324 & 0 & 2.1 & 213 & 2.4 \\
\hline Outpatient & 2.2 & 1 & 1 & 2 & 0 & 0 & 1 & 0.0 \\
\hline Professional care & 25.8 & 697 & 478 & 956 & 0 & 7.2 & 689 & 7.7 \\
\hline Medication & 100 & 1070 & 820 & 1321 & 545 & 11.1 & 1127 & 12.5 \\
\hline Levodopa & 86.9 & 478 & 239 & 754 & 73 & 5 & 507 & 5.6 \\
\hline Dopamine agonist & 53.3 & 239 & 161 & 337 & 46 & 2.5 & 242 & 2.7 \\
\hline MAO inhibitor & 7.5 & 30 & 18 & 45 & 0 & 0.3 & 31 & 0.3 \\
\hline COMT inhibitor & 7.9 & 20 & 10 & 29 & 0 & 0.2 & 20 & 0.2 \\
\hline Anticholinergic antiparkinsonian medication & 2.2 & 1 & 0 & 2 & 0 & 0 & 1 & 0.0 \\
\hline Amantadine & 2.5 & 6 & 5 & 8 & 0 & 0.1 & 6 & 0.1 \\
\hline Antidepressant & 31.9 & 9 & 7 & 11 & 0 & 0.1 & 9 & 0.1 \\
\hline Antipsychotics & 26.8 & 5 & 3 & 7 & 0 & 0 & 5 & 0.1 \\
\hline Drugs for dementia & 19.3 & 12 & 9 & 15 & 0 & 0.1 & 12 & 0.1 \\
\hline Antihypotensive agent & 0.4 & 0 & 0 & 1 & 0 & 0 & 0 & 0.0 \\
\hline Other medication & 95.5 & 249 & 193 & 318 & 132 & 2.6 & 295 & 3.3 \\
\hline Indirect costs & 9.2 & 962 & 606 & 1337 & 0 & 10 & 962 & 10.7 \\
\hline Early retirement or unemployment & 8.3 & 926 & 585 & 1267 & 0 & 9.6 & 926 & 10.3 \\
\hline Sick leave & 0.9 & 63 & 0 & 89 & 0 & 0.7 & 36 & 0.4 \\
\hline Total costs & 100 & 9657 & 8362 & 11,193 & 7453 & 100 & 8995 & 100 \\
\hline Informal care & 82.5 & 10,964 & 10,012 & 11,952 & 13,289 & 113.5 & 10,964 & 121.9 \\
\hline
\end{tabular}

$C I$ confidence interval, $C O M T$ catechol- $O$-methyltransferase, $M A O$ monoamine oxidase inhibitor ${ }^{\mathrm{a}} 95 \%$ bias corrected and accelerated bootstrap CI from the original data set

${ }^{\mathrm{b}}$ Percentage of patients for whom costs were incurred 


\subsubsection{Drug Treatment}

The costs of medication were $€ 1070$ (11.1\%). Medication was mostly driven by levodopa and dopamine agonists. Approximately $96 \%$ of the patients took further medication outside of therapy for PD.

\subsubsection{Professional Care}

The mean costs of professional care were $€ 697$ (7.2\%). Therefore, the parameter only accounts for a small proportion of the total costs. Only $25.8 \%$ of the patients received professional care.

\subsubsection{Further Direct Costs}

The remaining direct costs in descending order amounted to $€ 639$ (6.7\%) for ancillary therapy, €206 (2.1\%) for rehabilitation, $€ 188$ (1.9\%) for medical aids, and $€ 177$ (1.8\%) for physician visits.

\subsection{Indirect Costs}

Indirect costs were incurred by $9.2 \%$ of the patients. The indirect cost amounted to $€ 962$ (10\%). Indirect costs were mainly driven by early retirement or unemployment of the patients with PD.

\subsection{Informal Care}

A total of $83 \%$ of the patients received informal care. The mean cost for the 3-month period of informal care was $€ 10,964$. Thus, the informal care costs exceeded the total costs charged by $13.5 \%$.

\subsection{Cost of IIIness: Imputed Data Sets}

In summary, the imputed data sets showed comparable results. With regard to the subcategories of direct costs, there were almost no changes and the differences amounted to only a few Euros. However, there is a larger difference in the sum of all direct costs ( $€ 8749$ vs $€ 8033$ ). This is owing to the fact that within the original data set only complete cases were included in the calculation of the mean. Within the subcategories, individually missing values were less noticeable because the majority of the data for the respective parameter was complete. The mean value of the direct cost deviates more strongly because it results from the mean of all complete cases over all parameters. As the indirect costs were identical, the difference that occurred for the total costs was the same.

\subsection{Cost-Driving Factors: Univariate Analysis}

Tables 2-4 of the ESM show the results of this analysis for total, direct, and indirect costs. In terms of total costs, no significant differences were found between tested groups of the parameters. For direct costs, nonparametric tests indicat significant differences between groups of (1) mentation, behavior, and mood. For indirect costs, (1) age, (2) HY, (3) Schwab and England, (4) complications of therapy, and (5) EQ-5D-3L we found significant differences between the groups. Within the areas tested, there were no significant differences in sex or insurance status. In addition, the groups of activities of daily living, motor examination, and duration of the disease showed no significant differences. However, these are not ordinal or nominal variables; hence, the analysis could be inaccurate. Therefore, they were also transferred to the multiple regression analysis. Table 5 of the ESM shows the separate analysis for informal care. There were significant differences between the groups of (1) sex, (2) HY, (3) Schwab and England, (4) activities of daily living, (5) motor examination, (6) complications of therapy, and (7) EQ-5D-3L.

\subsection{Cost-Driving Factors: Multiple Regression Analysis}

Based on the cost drivers and their effects on total, direct, and indirect costs, the results are presented in Table 4. The duration of the disease and age were identified as cost-driving factors for total costs. The duration of the disease was a driver of direct costs. However, this only applied to the original data set; within the imputed data set, the duration of the disease was not a significant cost driver for direct costs $(p=0.068)$. For indirect costs, only the age of the patients was a significant cost-driving factor. Additionally, Table 5 shows the results with included informal care costs. The duration of the disease and age remain significant cost drivers for total costs. While the respective costs increased with increasing duration of the disease, they decreased with increasing age. In addition, the Unified Parkinson's Disease Rating Scale activities of daily living also showed a significant positive cost-driving effect. The influence of all other factors previously identified as potential cost drivers by univariate analysis, was not confirmed by the multiple regression analysis. 
Table 4 Multiple regression analysis of potential cost-driving factors

\begin{tabular}{|c|c|c|c|c|c|c|c|c|}
\hline \multirow[t]{4}{*}{ Parameter } & \multicolumn{8}{|c|}{ Total costs } \\
\hline & \multicolumn{4}{|c|}{ Original data } & \multicolumn{4}{|c|}{ Imputed data } \\
\hline & \multirow[t]{2}{*}{$\overline{\beta^{\mathrm{b}}}$} & \multicolumn{2}{|l|}{$95 \% \mathrm{CI}^{\mathrm{a}}$} & \multirow[t]{2}{*}{$P$ value } & \multirow[t]{2}{*}{$\overline{\beta^{\mathrm{b}}}$} & \multicolumn{2}{|l|}{$95 \% \mathrm{CI}^{\mathrm{a}}$} & \multirow[t]{2}{*}{$P$ value } \\
\hline & & Lower & Upper & & & Lower & Upper & \\
\hline Age & -0.029 & -0.047 & -0.010 & 0.003 & -0.025 & -0.042 & -0.009 & 0.003 \\
\hline \multicolumn{9}{|l|}{ UPDRS } \\
\hline \multicolumn{9}{|l|}{ Hoehn and Yahr } \\
\hline III & 0.493 & -0.287 & 1.273 & 0.215 & 0.368 & -0.298 & 1.034 & 0.279 \\
\hline IV & -0.113 & -0.533 & 0.308 & 0.599 & -0.065 & -0.423 & 0.293 & 0.723 \\
\hline $\mathrm{V}$ & - & - & - & - & - & - & - & - \\
\hline \multicolumn{9}{|l|}{ Schwab and England } \\
\hline 0.7 & - & - & - & - & - & - & - & - \\
\hline 0.6 & -0.030 & -2.038 & 1.979 & 0.977 & 0.102 & -1.355 & 1.559 & 0.891 \\
\hline 0.5 & 0.360 & -1.417 & 2.136 & 0.692 & -0.057 & -1.398 & 1.285 & 0.934 \\
\hline 0.4 & 0.271 & -1.516 & 2.057 & 0.766 & -0.092 & -1.459 & 1.275 & 0.895 \\
\hline 0.3 & 0.157 & -1.623 & 1.938 & 0.863 & -0.152 & -1.518 & 1.213 & 0.827 \\
\hline 0.2 & 0.244 & -1.654 & 2.143 & 0.801 & -0.162 & -1.617 & 1.292 & 0.827 \\
\hline 0.1 & -0.136 & -2.048 & 1.775 & 0.889 & -0.671 & -2.168 & 0.827 & 0.380 \\
\hline 0 & 0.263 & -1.784 & 2.311 & 0.801 & 0.101 & -1.501 & 1.703 & 0.901 \\
\hline Mentation, behavior, and mood & -0.021 & -0.082 & 0.041 & 0.512 & -0.007 & -0.057 & 0.044 & 0.791 \\
\hline Activities of daily living & 0.018 & -0.015 & 0.052 & 0.285 & 0.018 & -0.012 & 0.047 & 0.243 \\
\hline Motor examination & 0.003 & -0.012 & 0.018 & 0.677 & 0.000 & -0.012 & 0.013 & 0.949 \\
\hline Complications of therapy & -0.022 & -0.070 & 0.026 & 0.361 & -0.009 & -0.053 & 0.034 & 0.669 \\
\hline EQ-5D-3L & -0.337 & -1.047 & 0.374 & 0.353 & -0.310 & -0.919 & 0.299 & 0.318 \\
\hline \multirow[t]{2}{*}{ Duration of the disease (years) } & 0.030 & 0.010 & 0.049 & 0.003 & 0.018 & 0.001 & 0.036 & 0.039 \\
\hline & \multicolumn{8}{|c|}{$\begin{array}{l}\text { Goodness of fit: deviance [value/df] }=0.928 \text { for original data; between } 0.979 \text { and } 1.010 \text { for imputed } \\
\text { datasets I Pearson Chi-square [value/df]: } 0.731 \text { for original data; between } 0.857 \text { and } 0.875 \text { for imputed } \\
\text { datasets }\end{array}$} \\
\hline Age & -0.006 & -0.027 & 0.015 & 0.571 & -0.003 & -0.022 & 0.015 & 0.715 \\
\hline \multicolumn{9}{|l|}{ UPDRS } \\
\hline \multicolumn{9}{|l|}{ Hoehn and Yahr } \\
\hline III & 0.333 & -0.480 & 1.145 & 0.422 & 0.183 & -0.510 & 0.876 & 0.604 \\
\hline IV & -0.210 & -0.640 & 0.219 & 0.337 & -0.130 & -0.493 & 0.233 & 0.483 \\
\hline V & - & - & - & - & - & - & - & - \\
\hline \multicolumn{9}{|l|}{ Schwab and England } \\
\hline 0.7 & - & - & - & - & - & - & - & - \\
\hline 0.6 & -0.478 & -2.552 & 1.597 & 0.652 & 0.425 & -1.096 & 1.947 & 0.584 \\
\hline 0.5 & 0.404 & -1.446 & 2.255 & 0.668 & 0.508 & -0.883 & 1.899 & 0.474 \\
\hline 0.4 & 0.243 & -1.619 & 2.106 & 0.798 & 0.420 & -0.988 & 1.827 & 0.559 \\
\hline 0.3 & 0.166 & -1.687 & 2.019 & 0.860 & 0.369 & -1.033 & 1.770 & 0.606 \\
\hline 0.2 & 0.272 & -1.701 & 2.246 & 0.787 & 0.400 & -1.090 & 1.891 & 0.599 \\
\hline 0.1 & -0.152 & -2.142 & 1.837 & 0.881 & -0.149 & -1.682 & 1.385 & 0.849 \\
\hline 0 & 0.339 & -1.790 & 2.468 & 0.755 & 0.630 & -1.012 & 2.273 & 0.452 \\
\hline Mentation, behavior, and mood & -0.031 & -0.096 & 0.034 & 0.348 & -0.015 & -0.067 & 0.038 & 0.586 \\
\hline Activities of daily living & 0.019 & -0.016 & 0.054 & 0.284 & 0.022 & -0.009 & 0.053 & 0.166 \\
\hline Motor examination & 0.004 & -0.012 & 0.019 & 0.621 & 0.000 & -0.013 & 0.012 & 0.962 \\
\hline Complications of therapy & -0.035 & -0.084 & 0.013 & 0.154 & -0.020 & -0.064 & 0.024 & 0.370 \\
\hline EQ-5D-3L & -0.185 & -0.920 & 0.549 & 0.621 & -0.173 & -0.809 & 0.464 & 0.595 \\
\hline Duration of the disease (years) & 0.030 & 0.009 & 0.050 & 0.005 & 0.017 & 0.001 & 0.035 & 0.068 \\
\hline
\end{tabular}


Table 4 (continued)

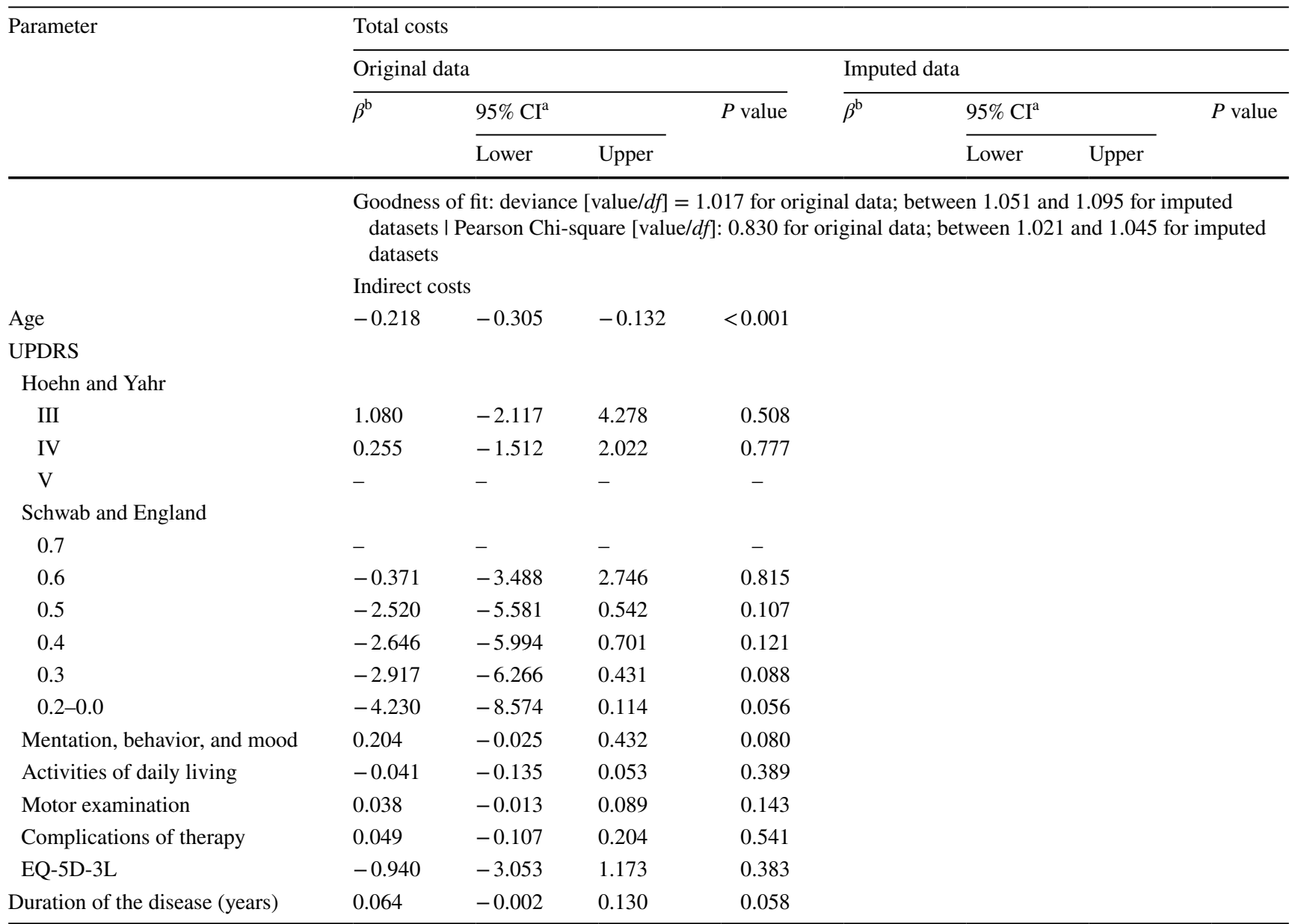

Goodness of fit: deviance [value/df] $=0.200$ । Pearson Chi-square [value/df]: 0.287

CI confidence interval, UPDRS Unified Parkinson's Disease Rating Scale

${ }^{\mathrm{a}} 95 \%$ Wald CI for $\beta$

${ }^{\mathrm{b}}$ Regression coefficient, where a value a value of 0 indicates no influence and a value $>0(<0)$ indicates a positive (negative) influence

\section{Discussion}

The aim of this study was to evaluate the health economic resource utilization of patients in the late stage of PD in Germany. The results indicated that the total and direct costs of the imputed data sets were more robust when the subcategories were combined, hence they are referred to in this section. For better comparability, the costs of the studies discussed below were inflated to the year 2016 using the German [32] or European consumer price index [42], and were extrapolated to 1 year if necessary.

The mean total cost without informal care of the investigated group was $€ 8995$ over the 3-month period, and extrapolated to 1 year, the cost was $€ 35,980$. Currently, no studies are available that evaluated the resource utilization in the late stages of the disease; however, a comparison of pertinent studies (for a comparison, see Table 1 of the ESM) based on HY stages is feasible. Within the German healthcare system the calculated costs of PD by Reese et al. [18] (6\% late-stage patients) and Spottke et al. [43] (10\% latestage patients), amounted to $€ 19,274$ and $€ 24,737$ per year, respectively. It is worth mentioning that the former study [18] included informal care costs of $€ 1156$ within the total costs, whereas the latter study [43] did not calculate informal care costs. Thus, the comparison indicates a significant increase in total costs. On a European level the comparison also indicates an increase in the total costs (see Table 1 of the ESM). The total costs with only a few patients in the late stages of the disease were $€ 18,835$ in Italy (4\% latestage patients) [44] and $€ 21,604$ in Austria (16\% late-stage patients) [45]. The amount of informal care costs in these studies was $€ 4425$ [44] and $€ 7084$ [45]. Furthermore, there are pertinent studies that do not allow a comparison of the patient population based on the HY stages, but because of 
Table 5 Multiple regression analysis of potential cost-driving factors (informal care included)

\begin{tabular}{|c|c|c|c|c|}
\hline \multirow[t]{4}{*}{ Parameter } & \multicolumn{4}{|c|}{ Total costs } \\
\hline & \multicolumn{4}{|c|}{ Imputed data } \\
\hline & \multirow[t]{2}{*}{$\beta^{\mathrm{b}}$} & \multicolumn{2}{|l|}{$95 \% \mathrm{CI}^{\mathrm{a}}$} & \multirow[t]{2}{*}{$P$ value } \\
\hline & & Lower & Upper & \\
\hline \multicolumn{5}{|l|}{ Sex } \\
\hline Female & -0.083 & -0.247 & 0.081 & 0.321 \\
\hline Male & - & - & - & - \\
\hline Age & -0.014 & -0.026 & -0.002 & 0.018 \\
\hline \multicolumn{5}{|l|}{ UPDRS } \\
\hline \multicolumn{5}{|l|}{ Hoehn and Yahr } \\
\hline III & -0.207 & -0.651 & 0.238 & 0.362 \\
\hline IV & -0.108 & -0.338 & 0.122 & 0.358 \\
\hline V & & & & \\
\hline \multicolumn{5}{|l|}{ Schwab and England } \\
\hline 0.7 & & & & \\
\hline 0.6 & 0.033 & -0.897 & 0.963 & 0.944 \\
\hline 0.5 & 0.303 & -0.524 & 1.131 & 0.472 \\
\hline 0.4 & 0.191 & -0.659 & 1.042 & 0.660 \\
\hline 0.3 & 0.287 & -0.564 & 1.138 & 0.509 \\
\hline 0.2 & 0.319 & -0.587 & 1.225 & 0.491 \\
\hline 0.1 & 0.146 & -0.803 & 1.095 & 0.763 \\
\hline 0 & 0.373 & -0.647 & 1.394 & 0.474 \\
\hline $\begin{array}{l}\text { Mentation, behavior, and } \\
\text { mood }\end{array}$ & 0.015 & -0.018 & 0.048 & 0.381 \\
\hline Activities of daily living & 0.020 & 0.002 & 0.039 & 0.030 \\
\hline Motor examination & -0.006 & -0.014 & 0.002 & 0.134 \\
\hline Complications of therapy & -0.008 & -0.035 & 0.020 & 0.587 \\
\hline EQ-5D-3L & -0.185 & -0.570 & 0.200 & 0.346 \\
\hline Duration of the disease (years) & 0.015 & 0.003 & 0.027 & 0.011 \\
\hline
\end{tabular}

Goodness of fit: deviance [value/df] $=0.277$ । Pearson chi-square [value/df]: 0.230

CI confidence interval, UPDRS Unified Parkinson's Disease Rating Scale

${ }^{\mathrm{a}} 95 \%$ Wald CI for $\beta$

${ }^{\mathrm{b}}$ Regression coefficient, where a value a value of 0 indicates no influence and a value $>0(<0)$ indicates a positive (negative) influence

their study design they cover a less late diseased population on average [9, 10]. Jennum et al. calculated costs of $€ 11,323$ (Denmark) for patients who received their PD diagnosis in the primary or secondary sector in hospitals [10]. Olesen et al. estimated the total costs in Europe at $€ 11,934$ based on a systematic literature review [9].

In our study, the mean direct cost was $€ 8033$ over the 3 -month period, and extrapolated to 1 year, the direct cost was $€ 32,132$. The direct costs of the mentioned German studies were $€ 13,526$ [18] and $€ 13,219$ [43]. The European study by Olesen et al. [9] calculated direct costs of $€ 10,746$. Further direct costs were $€ 13,145$ (Italy) [44], $€ 12,962$
(Austria) [45], and $€ 9370$ (Denmark) [10]. Thus, the comparison showed a distinct increase in direct costs at both the national and European level. Within the direct costs of the CLaSP study, hospitalization was the biggest cost item with $€ 19,968$ per year $(56 \%)$. The patients spent approximately 7.2 days in the hospital during the 3-month study period. Of these, $83 \%$ of hospitalizations were directly linked to PD. Even though hospital days generally increase with age, the comparable general population age group between 70 and 74 years in Germany spends only approximately 0.73 days in hospital in the same period (age group 60-64 years: 0.45 days; age group 85-89 years: 1.45 days) [46]. At the same time, the number of hospital admissions was also increased. In the CLaSP study, $52 \%$ of the patients were hospitalized. In contrast, previous studies showed a considerably lower hospitalization rate with $10-12 \%[18,43]$, whereas the average population aged 70-74 years in Germany has 0.10 hospital cases per patient in the same period (age group 60-64 years has 0.06 cases and age group $85-89$ years has 0.16 cases) [46]. Thus, there seems to be an increase in hospital stays, which was also demonstrated in a recent analysis on case number development of PD inpatient treatment in Germany [47]. At the same time, the drug cost increased with $€ 4508$ compared with the previous studies with $€ 3327$ [18] and $€ 3749$ [43]. The costs for professional care have also increased, at $€ 2756$ per year, compared with those of a less severely diseased patient population at $€ 229$ [18].

The mean indirect cost was $€ 962$ for the 3-month period, and extrapolated to 1 year, the cost was $€ 3848$. In total, only one patient was still working. The comparison with previous German studies with €5748 [18] and €7843 [43] showed thereby a considerable decrease, which is mainly owing to the older age of the patients $(74.06 \pm 8.39$ years vs $63.1 \pm$ 9.9 years [18] and $67.3 \pm 9.6$ years [43]).

Only a few studies have evaluated costs of informal care (see Table 1 of the ESM). Therefore, a precise comparison of costs and factors associated with costs for informal care in our study with the published literature is difficult, in particular as informal care was evaluated differently with respect to cost as there is no current consensus on what factors to sum up when calculating informal care costs [48, 49]. However, some general comments about cost determinants can be made. In our study, the separately quarterly calculated informal care cost was $€ 10,964$, and extrapolated to 1 year, the cost was $€ 43,856$. The mean caring time per week was 68 hours. In Findley et al. [50], patients in the late stage of PD were investigated according the time spent in the "off" state. In their case, informal care time was 34 hours per week and also more dominant than professional care. In this context, it should be mentioned that the HY III patients included by Findley et al. represent approximately $54 \%$ of the patients. Campenhausen et al. [7] also identified informal care as the most common form of home care for patients with PD 
in Europe, from 10 to 56 hours per week. These observations also appeared in our data, according to which $83 \%$ of patients receive informal care but only $28 \%$ receive professional care. This result is higher than data published by the German federal statistical office, where approximately $70 \%$ of persons in need of care are treated by informal CGs with 29\% cared for by professional nurses [51]. The reasons for the high number of informal care as well as the difference can only be speculated, partly because of the desire of the patients and their CGs to have their family members at home and in well-known surroundings and owing to the financial incentive of the German nursing care insurance.

Total costs were found to increase with progressing disease stage with a significant correlation between increasing HY stage and increasing costs in Germany [18, 43]. At the same time, in our multiple regression analyses, similar to a study by Tamás et al. in Hungary [8], the duration of the disease showed a significant positive influence on total and direct costs. This raises the question why the HY stages were not a significant cost driver in our data, but the duration of the disease was a significant cost driver. First, it is noticeable that our HY III patients were represented in small numbers (14/228) and caused slightly higher total costs than the patients from stages IV and V. These HY III patients were included in the first place because they had higher scores on the Schwab and England Scale. Accordingly, the costs of the patients in HY III were more similar to those of HY IV and $\mathrm{V}$ than in the above-mentioned studies, as they were affected by both a small group size and the study's inclusion criteria. The included HY III patients were therefore not representative. A comparison of the HY stages and the duration of the disease also revealed that on average our patients in HY IV had a longer disease duration with a mean of 13.8 years than our patients in HY V with 11.0 years. The patients in HY III had a mean disease duration of 8.9 years. For comparison, a study of disability and progression of PD with 419 patients showed an average progression towards HY III after a disease duration of 5.5 years, towards HY IV after 7.5 years, and towards HY V after 9.7 years [52]. At the same time, approximately $60 \%$ of the patients had progressed towards HY V after 10 years [52]. In our data, only approximately $24 \%$ of patients with a disease duration of 10 years or longer were in HY V. However, approximately $72 \%$ were in HY IV and 5\% in HY III. We therefore hypothesize that the duration of the disease was more sensitive in relation to our patient cohort. However, this effect may not necessarily apply to all patients in the late stage of the disease, especially because it seems atypical that our HY IV patients had a longer average duration of disease than HY V patients. Second, our tests only refer to patients with late-stage parkinsonism. It is therefore more likely that there is a significant correlation between an increase in costs and an increase in HY stages provided the analyses includes all stages of the disease.
The finding that indirect costs were negatively driven by the age of the patients is in line with the notion of modelling indirect costs using the human capital approach. The relatively small productivity losses result from the high average age of patients in combination with this approach.

When informal care costs were included in the regression, patients who were less able to manage activities of daily living also showed significantly higher costs. This increasing inability was thus mainly compensated by informal CGs.

In summary, costs in Germany were largely caused by hospitalization and informal care. The challenge is therefore to what extent healthcare for these patients can be optimized in terms of (1) reducing hospital stays and (2) relieving the burden on relatives and increasing the level of support. A care network in which physicians, a PD nurse specialist (PDNS), therapists, and CGs specialized in the treatment of PD provide an integrated service could enable improved healthcare and may reduce healthcare expenditures [53]. In addition, newer approaches to achieve patient contact, especially in remote areas, using telemedicine may also be considered and integrated to allow a better care with a lowered resource use $[54,55]$.

A framework concept for the structured/integrated care of patients with PD in Germany was already proposed in 2007 [56], but newer approaches are available [57]. In this context, the PDNS in particular may play a key role. Although in Germany, the organization of such a specialist has not yet become established all over the country, in the UK and the Netherlands, they have been working since 1989 and 1997, respectively. The PDNS could help to (1) assess the needs of patients and relatives, (2) develop a patient-centered plan, (3) coordinate and monitor the developed plan, (4) coordinate the collaboration with other professionals, and (5) represent the needs of patients and relatives within the process [58]. Although this proposition may sound intuitive, a positive effect of a PDNS has not been evaluated in Germany compared to conventional alternatives and cannot be sufficiently supported by results from previous studies $[59,60]$. There are also no study results on cost effectiveness available until now. Evaluating the reasons for the hospitalization of our patient group, we believe that $57 \%$ of the cases could be treated with the help of such an integrated network instead of an inpatient hospital stay. This is especially achievable for patients needing a drug modification, which is responsible for $28 \%$ of the hospital stays. Against the background of demographic change and a simultaneously increasing life expectancy of the German population, the challenges in dealing with late-stage PD will become even greater [61]. The results from our study should be used as an opportunity to reconsider the support provided to these patients and their CG. 


\subsection{Study Limitations}

Because of the relatively large number of tested factors and covariates within the multiple regression analysis in relation to the sample size, an inefficiency of the estimates cannot be excluded. A further limitation may be the different number of patients in the participating centers. Location-related seasonal characteristics of the data are not evenly included in the study. Many of the patients or their CG have indicated a particularly high level of informal care. In 61 cases, the informal care time was adjusted in this study. It cannot be assumed with certainty that the informal caring time was correctly represented. Accordingly, the results may be biased regarding informal care. However, we have tried to minimize the distortion by examining informal care separately. It should also be considered that only severely ill patients with PD were included in our study. Accordingly, the identification of cost-driving factors cannot be extrapolated to the entire group of patients with PD.

\section{Conclusions}

This study observed that the progression of the disease leads to a considerable increase in societal costs. This is underlined by identifying the duration of the disease as a main cost driver. Losses in productivity only play a minor role, as many of the patients have already reached retirement age. This is indicated by the negative correlation between costs with increasing age. The increased costs are mainly caused by an increase in hospitalization and in the need for care. This confirmed the initially expected effects of late-stage parkinsonism in terms of higher costs with higher hospitalization and need for care. Within the 3-month study period, approximately every second patient was treated as an inpatient in hospital. Notably, only $26 \%$ of our patients received professional care. The great burden therefore lies with informal CG, and consideration should therefore be given to how this burden on informal CG can be relieved. In particular, an integrated care network could help to provide a better healthcare environment for these patients and their relatives. Our findings imply that it is important to take a societal viewpoint and include factors associated with the informal care of patients with PD when taking decisions for further resource allocation.

Supplementary Information The online version contains supplementary material available at https://doi.org/10.1007/s40273-021-01011-y.

\section{Declarations}

Funding Open Access funding enabled and organized by Projekt DEAL. The CLaSP study is funded by the European Commission (Joint Programme, Neurodegenerative Disease Research "European research projects for the evaluation of health care policies, strategies and interventions for Neurodegenerative Diseases") through national funding bodies in all six countries (Economic and Social Research Council ES/ L009250/1; BMBF, Marburg, Germany: 01ED1403A, Munich, Germany: 01ED1403B, Bordeaux, France: ANR-13-JPHC-0001-07, Lisbon, Portugal: HC/0002/2012, Lund, Sweden: HC-559-002, Nijmegen, Holland, the Netherlands: 733051003). Anette Schrag was supported by the National Institute for Health Research UCL/UCLH Biomedical Research Centre.

Conflict of interest Christopher Kruse, Sabrina Kretschmer, Anna Lipinski, Malte Verheyen, David Mengel, Monika Balzer-Geldsetzer, Stefan Lorenzl, Carmen Richinger, Christian Schmotz, Lars Tönges, Dirk Woitalla, Stephan Klebe, Anette Schrag, and Richard Dodel have no conflicts of interest that are directly relevant to the content of this article.

Ethics approval All study sites received approval of their local ethics committee before study start. The CLaSP study was conducted in compliance with the Helsinki Declaration, i.e., detailed oral and written information was given to the patients and their informant to ensure that the patient fully understood the potential risks and benefits of the study. The study protocol was approved by the local ethics committees of all participating study sites (London: Camden and Islington NRES Committee 14/LO/0612, Bordeaux: South West and Overseas Protection Committee III [South West and Overseas Protection Committee], 2014-A01501-46, Lisbon: Centro Hospitalar Lisboa Norte, DIRCLN-19SET2014-275, Lund: EPN Regionala Etikprovningsnamnden: Lund[(EPN Regional Ethics Name: Lund], JPND NC 559-002, Marburg: Ethik-Kommission der Philipps-Universität Marburg und Ethikkommission bei der Landesarztekammer Hessen [Ethics Commission at the State Medical Association Hesse], MC 309/2014, Munich: Ethikkommission bei der LMU Munchen [Ethics Committee at the LMU Munchen], 193-14, Nijmegen: Radboud Universitair Medisch Centrum, Concernstaf Kwaliteit en Veiligheid, Commissie Mensgebonden Onderzoek Regio Arnhem-Nijmegen [Radboud University Medical Center, Group Staff Quality and Safety Human Research Committee, Arnhem-Nijmegen region], DJ/CMO300).

Consent to participate Participants (patients and their caregivers) were included in the study after giving their written informed consent. Where the patient lacked capacity to give consent to the study because of severe cognitive impairment, the decision on study participation was made by a legal guardian or consultee, depending on the ethical and legal requirements at each site. All participants (patients and caregivers) could withdraw from the study at any point in time without any negative implications.

Consent for publication All authors have read the final manuscript and consented publication.

Availability of data and material The datasets generated during and/or analyzed during the current study are available from the corresponding author on a reasonable request.

Code availability The statistical analysis was performed using IBM SPSS Statistics, Version 26.0.0.0 (IBM, Armonk, NY, USA). No custom code was used. 
Author contributions AS and RD designed the study and ensured its overall coordination. RD and MBG were responsible for the economic study. CK built the costing database and performed the economic analysis. SK, AL, MV, DM, SL, CR, CS, LT, DW, SK, and MLW were responsible for the management and supervision of participants' clinical follow-up at the different sites. They also collected clinical data and the socio-economic data. The manuscript was drafted by $\mathrm{CK}$ and RD. All authors made critical comments on the manuscript draft and approved the final version of the manuscript for submission and agreed to be responsible for all aspects of the work. Principal investigators of the CLaSP study group: Bloem B, Coelho M, Ferreira JJ, Hommel ALAJ, Lorenzl S, Meissner W, Odin P, Wittenberg M.

Open Access This article is licensed under a Creative Commons Attribution-NonCommercial 4.0 International License, which permits any non-commercial use, sharing, adaptation, distribution and reproduction in any medium or format, as long as you give appropriate credit to the original author(s) and the source, provide a link to the Creative Commons licence, and indicate if changes were made. The images or other third party material in this article are included in the article's Creative Commons licence, unless indicated otherwise in a credit line to the material. If material is not included in the article's Creative Commons licence and your intended use is not permitted by statutory regulation or exceeds the permitted use, you will need to obtain permission directly from the copyright holder. To view a copy of this licence, visit http://creativecommons.org/licenses/by-nc/4.0/.

\section{References}

1. Gustavsson A, Svensson M, Jacobi F, Allgulander C, Alonso J, Beghi E, et al. Cost of disorders of the brain in Europe 2010. Eur Neuropsychopharmacol. 2011;21:718-79. https://doi.org/10. 1016/j.euroneuro.2011.08.008.

2. Dorsey ER, Elbaz A, Nichols E, Abd-Allah F, Abdelalim A, Adsuar JC, et al. Global, regional, and national burden of Parkinson's disease, 1990-2016: a systematic analysis for the Global Burden of Disease Study 2016. Lancet Neurol. 2018;17:939-53. https://doi.org/10.1016/S1474-4422(18)30295-3.

3. Coelho M, Ferreira J, Rosa M, Sampaio C. Treatment options for non-motor symptoms in late-stage Parkinson's disease. Expert Opin Pharmacother. 2008;9:523-35. https://doi.org/10.1517/ 14656566.9.4.523.

4. Hely MA, Morris JGL, Reid WGJ, Trafficante R. Sydney multicenter study of Parkinson's disease: non-L-dopa-responsive problems dominate at 15 years. Mov Disord. 2005;20:190-9. https:// doi.org/10.1002/mds.20324.

5. Tolosa E, Wenning G, Poewe W. The diagnosis of Parkinson's disease. Lancet Neurol. 2006;5:75-86. https://doi.org/10.1016/ S1474-4422(05)70285-4.

6. Hoehn MM, Yahr MD. Parkinsonism: onset, progression and mortality. Neurology. 1967;17:427-42. https://doi.org/10.1212/wnl. 17.5.427.

7. von Campenhausen S, Winter Y, Rodrigues e silva A, Sampaio C, Ruzicka E, Barone P, et al. Costs of illness and care in Parkinson's disease: an evaluation in six countries. Eur Neuropsychopharmacol. 2011;21:180-91. https://doi.org/10.1016/j.euroneuro.2010. 08.002 .

8. Tamás G, Gulácsi L, Bereczki D, Baji P, Takáts A, Brodszky V, Péntek M. Quality of life and costs in Parkinson's disease: a cross sectional study in Hungary. PLoS ONE. 2014;9:e107704. https:// doi.org/10.1371/journal.pone.0107704.
9. Olesen J, Gustavsson A, Svensson M, Wittchen H-U, Jönsson B. The economic cost of brain disorders in Europe. Eur J Neurol. 2012;19:155-62. https://doi.org/10.1111/j.1468-1331.2011. 03590.x.

10. Jennum P, Zoetmulder M, Korbo L, Kjellberg J. The healthrelated, social, and economic consequences of parkinsonism: a controlled national study. J Neurol. 2011;258:1497-506. https:// doi.org/10.1007/s00415-011-5969-1.

11. Vossius C, Nilsen OB, Larsen JP. Parkinson's disease and nursing home placement: the economic impact of the need for care. Eur J Neurol. 2009;16:194-200. https://doi.org/10.1111/j.1468-1331. 2008.02380.x.

12. Noyes K, Liu H, Li Y, Holloway R, Dick AW. Economic burden associated with Parkinson's disease on elderly Medicare beneficiaries. Mov Disord. 2006;21:362-72. https://doi.org/10.1002/ mds. 20727.

13. Huse DM, Schulman K, Orsini L, Castelli-Haley J, Kennedy S, Lenhart G. Burden of illness in Parkinson's disease. Mov Disord. 2005;20:1449-54. https://doi.org/10.1002/mds.20609.

14. Kowal SL, Dall TM, Chakrabarti R, Storm MV, Jain A. The current and projected economic burden of Parkinson's disease in the United States. Mov Disord. 2013;28:311-8. https://doi. org/10.1002/mds.25292.

15. Cordato DJ, Schwartz R, Abbott E, Saunders R, Morfis L. A comparison of health-care costs involved in treating people with and without Parkinson's disease in Southern Sydney, New South Wales Australia. J Clin Neurosci. 2006;13:655-8. https://doi. org/10.1016/j.jocn.2005.09.006.

16. Zhao YJ, Tan LCS, Li SC, Au WL, Seah SH, Lau PN, et al. Economic burden of Parkinson's disease in Singapore. Eur J Neurol. 2011;18:519-26. https://doi.org/10.1111/j.1468-1331. 2010.03210.x.

17. Coelho M, Ferreira JJ. Late-stage Parkinson disease. Nat Rev Neurol. 2012;8:435-42. https://doi.org/10.1038/nrneurol.2012. 126.

18. Reese JP, Winter Y, Balzer-Geldsetzer M, Bötzel K, Eggert K, Oertel WH, et al. Morbus Parkinson: Krankheitskosten einer ambulanten Patientenkohorte. Gesundheitswesen. 2011;73:22-9. https://doi.org/10.1055/s-0030-1247571.

19. Valldeoriola F, Coronell C, Pont C, Buongiorno MT, Cámara A, Gaig C, Compta Y. Socio-demographic and clinical factors influencing the adherence to treatment in Parkinson's disease: the ADHESON study. Eur J Neurol. 2011;18:980-7. https://doi.org/ 10.1111/j.1468-1331.2010.03320.x.

20. Bach J-P, Riedel O, Klotsche J, Spottke A, Dodel R, Wittchen $\mathrm{H}-\mathrm{U}$. Impact of complications and comorbidities on treatment costs and health-related quality of life of patients with Parkinson's disease. J Neurol Sci. 2012;314:41-7. https://doi.org/10.1016/j. jns.2011.11.002.

21. Aarsland D, Larsen JP, Karlsen K, Lim NG, Tandberg E. Mental symptoms in Parkinson's disease are important to caregiver distress. Int J Geriatr Psychiatry. 1999;14:866-74.

22. Reese JP, Dams J, Winter Y, Balzer-Geldsetzer M, Oertel WH, Dodel R. Pharmacoeconomic considerations of treating patients with advanced Parkinson's disease. Expert Opin Pharmacother. 2012;13:939-58. https://doi.org/10.1517/14656566.2012.677435.

23. Balzer-Geldsetzer M, Ferreira J, Odin P, Bloem BR, Meissner WG, Lorenzl S, et al. Study protocol: Care of Late-Stage Parkinsonism (CLaSP): a longitudinal cohort study. BMC Neurol. 2018;18:185. https://doi.org/10.1186/s12883-018-1184-3.

24. Schwab J, England A. Projection technique for evaluating surgeyin Parkinson's disease. In: Gillingham F, Donaldson M, editors. Third Symposium on Parkinson's Disease, vol. 232. Edinburgh: Livingston; 1969. p. 152-7. 
25. Brooks R. EuroQol: the current state of play. Health Policy. 1996;37:53-72. https://doi.org/10.1016/0168-8510(96)00822-6.

26. EuroQol Research Foundation 2018. EQ-5D-3L user guide. December 2018. Available from: https://euroqol.org/wp-conte nt/uploads/2019/10/EQ-5D-3L-User-Guide_version-6.0.pdf. Accessed 18 Dec 2019.

27. Institut für Qualität und Wirtschaftlichkeit im Gesundheitswesen (IQWiG). Arbeitspapier Kostenbestimmung. 2009. Available from: https://www.iqwig.de/download/Arbeitspapier_Kostenbest immung_v_1_0.pdf. Accessed 14 Oct 2019.

28. Bock J-O, Brettschneider C, Seidl H, Bowles D, Holle R, Greiner W, König HH. Ermittlung standardisierter Bewertungssätze aus gesellschaftlicher Perspektive für die gesundheitsökonomische Evaluation. Gesundheitswesen. 2015;77:53-61. https://doi.org/ 10.1055/s-0034-1374621.

29. Krauth C, Hessel F, Hansmeier T, Wasem J, Seitz R, Schweikert B. Empirische Bewertungssätze in der gesundheitsökonomischen Evaluation: ein Vorschlag der AG Methoden der gesundheitsökonomischen Evaluation (AG MEG). Gesundheitswesen. 2005;67:736-46. https://doi.org/10.1055/s-2005-858698.

30. Bruckenberger E. Stagnation bei der Krankenhausfinanzierung. Führen und Wirtschaften im Krankenhaus. 1997;14:206-8.

31. BARMER. Heil- und Hilfsmittelreport 2018. 2018. Available from: https://www.barmer.de/blob/195652/0674c58e62431dd 80c2e9b77e4a71dcb/data/2019-01-16-barmer-heil--und-hilfsmitte lreport-2019.pdf. Accessed 22 Dec 2020.

32. Verbraucherpreisindizes für Deutschland. Jahresbericht 2020, Statistisches Bundesamt (Destatis), 2021. https://www.statistisc hebibliothek.de/mir/receive/DEHeft_mods_00133262.

33. Verband der Ersatzkassen (vdek). VDEK, Vergütungsvereinbarung für Wohlfahrtsverbände ab 01.02.18, Vertrag gemäß $\S 89$ SGBXI vom 26.10.2017 mit Gültigkeit für ab dem 01.02.2018 erbrachte Leistungen für Pflegedienste, die bei einem der an diesem Vertrag beteiligten Verbände der Freien Wohlfahrtspflege Bayern organisiert sind (AC/TK 3502 471). https://www. aokgesundheitspartner.de/imperia/md/gpp/by/pflege/ambulant/ by_pflege_ambulant_pv_gebuehren_wohlfahrt_vertrag_ab_01. 02.2018.pdf.

34. Vertrag gemäß § 89 SGB XI vom 02.11.2017 über die Vergütung von Pflegesachleistungen gemäß § 36 SGB XI mit Gültigkeit für abdem 01.02.2018 erbrachte Leistungen für Pflegedienste, die bei einem der an diesem Vertrag beteiligten Verbände der Leistungserbringer organisiert sind(AC/TK 3602 475). https://www. aokgesundheitspartner.de/imperia/md/gpp/by/pflege/ambulant/ by_pflege_ambulant_pv_gebuehren_arbeitskreis_vertrag_ab_ 01.02.2018.pdf.

35. Pflegebüro Bahrenberg Gruppe. Pflegedaten aus dem Leistungsmonat Juli 2019.

36. Liste R. Arzneimittelverzeichnis für Deutschland (einschließlich EU-Zulassungen und bestimmter Medizinprodukte). 56th ed. Frankfurt am Main: Rote Liste Service GmbH; 2016. p. 2016.

37. Durchschnittliche Bruttomonatsverdienste - Deutschland. Statistisches Bundesamt (Destatis). https://www.destatis.de/DE/ Themen/Arbeit/Verdienste/Verdienste-Verdienstunterschiede/ Tabellen/lange-reihe-deutschland.html. Accessed 15 Oct 2019.

38. InEK GmbH, Institut für das Entgeltsystem im Krankenhaus. Fallpauschalen-Katalog. 2016. Available from: https://www.gdrg.de/content/download/6646/50323/version/1/file/Fallpausch alen_Katalog_2016_151029.pdf. Accessed 10 Dec 2019.

39. Yap BW, Sim CH. Comparisons of various types of normality tests. J Stat Comput Simul. 2011;81:2141-55. https://doi.org/10. 1080/00949655.2010.520163.

40. Thompson SG, Barber JA. How should cost data in pragmatic randomised trials be analysed? BMJ. 2000;320:1197-200. https:// doi.org/10.1136/bmj.320.7243.1197.
41. Dodd S, Bassi A, Bodger K, Williamson P. A comparison of multivariable regression models to analyse cost data. J Eval Clin Pract. 2006;12:76-86. https://doi.org/10.1111/j.1365-2753.2006. 00610.x.

42. European Central Bank. HICP: indices, breakdown by purpose of consumption. 2020. Available from: https://www.ecb.europa. $\mathrm{eu} / \mathrm{stats} / \mathrm{services} / \mathrm{escb} / \mathrm{html} / \mathrm{table} . \mathrm{en} . \mathrm{html}$ ?id=JDF_ICP_COICOP_ INX. Accessed 23 Feb 2021.

43. Spottke AE, Reuter M, Machat O, Bornschein B, von Campenhausen S, Berger K, et al. Cost of illness and its predictors for Parkinson's disease in Germany. Pharmacoeconomics. 2005;23:81736. https://doi.org/10.2165/00019053-200523080-00007.

44. Winter Y, von Campenhausen S, Reese JP, Balzer-Geldsetzer M, Longo K, Spiga G, et al. Costs of Parkinson's disease and antiparkinsonian pharmacotherapy: an Italian cohort study. Neurodegener Dis. 2010;7:365-72. https://doi.org/10.1159/000302644.

45. von Campenhausen S, Winter Y, Gasser J, Seppi K, Reese J-P, Pfeiffer K-P, et al. Krankheitskosten und Versorgungssituation bei Morbus Parkinson-eine Analyse in Osterreich. Wien Klin Wochenschr. 2009;121:574-82. https://doi.org/10.1007/ s00508-009-1223-6.

46. BARMER Krankenhausreport 2020. Volume-Outcome im Krankenhaus, BARMER, Berlin, Schriftenreihe zur Gesundheitsanalyse - Band 25. https://www.barmer.de/blob/260366/d009a0b47c e8eb11cb8211411989e344/data/dl-report-komplett.pdf. Accessed 6 Jan 2021.

47. Tönges L, Bartig D, Muhlack S, Jost W, Gold R, Krogias C. Charakteristika und Dynamik der stationären Behandlung von Parkinson-Patienten in Deutschland Analyse von 1,5 Mio. Patientenfällen aus den Jahren 2010 bis 2015. Nervenarzt. 2019;90:16774. https://doi.org/10.1007/s00115-018-0590-5

48. van den Berg B, Brouwer WBF, Koopmanschap MA. Economic valuation of informal care: an overview of methods and applications. Eur J Health Econ. 2004;5:36-45. https://doi.org/10.1007/ s10198-003-0189-y.

49. Oliva-Moreno J, Trapero-Bertran M, Peña-Longobardo LM, Del Pozo-Rubio R. The valuation of informal care in cost-of-illness studies: a systematic review. Pharmacoeconomics. 2017;35:33145. https://doi.org/10.1007/s40273-016-0468-y.

50. Findley LJ, Wood E, Lowin J, Roeder C, Bergman A, Schifflers M. The economic burden of advanced Parkinson's disease: an analysis of a UK patient dataset. J Med Econ. 2011;14:130-9. https://doi.org/10.3111/13696998.2010.551164.

51. Pflegestatistik. Pflege im Rahmen der Pflegeversicherung. Deutschlandergebnisse 2019. Statistisches Bundesamt (Destatis) 2020. https://www.destatis.de/DE/Themen/Gesellschaft-Umwelt/ Gesundheit/Pflege/Publikationen/Downloads-Pflege/pflegedeut schlandergebnisse-5224001199004.pdf?_blob=publicationFile.

52. Marttila RJ, Rinne UK. Disability and progression in Parkinson's disease. Acta Neurol Scand. 1977;56:159-69. https://doi.org/10. 1111/j.1600-0404.1977.tb01420.x.

53. Bloem BR, Rompen L, de Vries NM, Klink A, Munneke M, Jeurissen P. ParkinsonNet: a low-cost health care innovation with a systems approach from the Netherlands. Health Aff (Millwood). 2017;36:1987-96. https://doi.org/10.1377/hlthaff.2017.0832.

54. Eggers C, Wellach I, Groppa S, Strothjohann M, Klucken J. Versorgung von Parkinson-Patienten in Deutschland: status quo und Perspektiven im Spiegel des digitalen Wandels. Nervenarzt. 2020. https://doi.org/10.1007/s00115-020-01027-3.

55. Ben-Pazi H, Browne P, Chan P, Cubo E, Guttman M, Hassan A, et $a l$. The promise of telemedicine for movement disorders: an interdisciplinary approach. Curr Neurol Neurosci Rep. 2018;18:26. https://doi.org/10.1007/s11910-018-0834-6.

56. Reuther P, Ehret R, Dodel R, Simonow A, Müngersdorf M, Oertel WH, Eggert K. Rahmenkonzept zur strukturierten/integrierten Versorung von Patienten mit Parkinson-Syndromen. In: Meier D, 
editors. Integrierte Versorgung in der Neurologie. Stuttgart: Georg Thieme Verlag; 2007. https://doi.org/10.1055/b-0034-35572.

57. Prell T, Siebecker F, Lorrain M, Eggers C, Lorenzl S, Klucken J, et al. Recommendations for standards of network care for patients with Parkinson's disease in Germany. J Clin Med. 2020;9:1455. https://doi.org/10.3390/jcm9051455.

58. Lennaerts H, Groot M, Rood B, Gilissen K, Tulp H, van Wensen E, et al. A guideline for Parkinson's disease nurse specialists, with recommendations for clinical practice. J Parkinsons Dis. 2017;7:749-54. https://doi.org/10.3233/JPD-171195.

59. Jarman B, Hurwitz B, Cook A, Bajekal M, Lee A. Effects of community based nurses specialising in Parkinson's disease on health outcome and costs: randomised controlled trial. BMJ. 2002;324:1072-5. https://doi.org/10.1136/bmj.324.7345.1072.

60. Reynolds H, Wilson-Barnett J, Richardson G. Evaluation of the role of the Parkinson's disease nurse specialist. Int J Nurs Stud. 2000;37:337-49. https://doi.org/10.1016/s0020-7489(00)00013-4.

61. Dorsey ER, Constantinescu R, Thompson JP, Biglan KM, Holloway RG, Kieburtz K, et al. Projected number of people with Parkinson disease in the most populous nations, 2005 through 2030. Neurology. 2007;68:384-6. https://doi.org/10.1212/01.wnl. 0000247740.47667 .03

\section{Authors and Affiliations}

\section{Christopher Kruse ${ }^{1}$. Sabrina Kretschmer ${ }^{1,2}$. Anna Lipinski ${ }^{1,2} \cdot$ Malte Verheyen $^{1} \cdot$ David Mengel $^{3}$. Monika Balzer-Geldsetzer ${ }^{1,2}$. Stefan Lorenzl ${ }^{4,5} \cdot$ Carmen Richinger $^{5} \cdot$ Christian Schmotz $^{5} \cdot$ Lars Tönges $^{6,7}$. Dirk Woitalla ${ }^{8}$. Stephan Klebe ${ }^{9} \cdot$ Anette Schrag $^{10} \cdot$ Richard Dodel $^{1,2}$}

1 Department of Geriatric Medicine, University of DuisburgEssen, Germaniastrasse 1-3, 45356 Essen, Germany

2 Department of Neurology, Philipps-University Marburg, Marburg, Germany

3 Department of Neurodegenerative Diseases, Center for Neurology and Hertie Institute for Clinical Brain Research, University of Tübingen, Tübingen, Germany

4 Department of Neurology, Ludwig-Maximilians University, Munich, Germany

5 Krankenhaus Agatharied GmbH, Institute of Nursing Science and Practice, Paracelsus Medical University, Salzburg, Austria
6 Department of Neurology, St. Josef-Hospital, Ruhr-University, Bochum, Germany

7 Neurodegeneration Research, Centre for Protein Diagnostics (ProDi), Ruhr-University, Bochum, Germany

8 Department of Neurology, St. Josef-Krankenhaus Kupferdreh, Essen, Germany

9 Department of Neurology, Essen University Hospital, Essen, Germany

10 Department of Neurology, King's College, London, UK 